funded by the $\mathrm{NIH}$ - came to a grinding halt, because his lab was then located in the government-funded Veterans Affairs Medical Center. "In the labs there was no engineering support, no mechanical support, nothing considered non-essential," he says. "Essentially the labs were in lockdown."

Another temporary funding measure could avert that outcome, but would simply prolong the uncertainty. At the Thomas Jefferson National Accelerator Facility in Newport News, Virginia, a temporary shutdown to upgrade the particle accelerator is scheduled for this year. Robert McKeown, the facility's deputy director for science, had been planning to hire extra people to work on the upgrade, to keep the project on track. But "if the funding situation continues two weeks at a time, I'm afraid we won't be able to make decisions to hire people".

The delay to a finalized 2011 budget also means that any cuts will feel more dramatic when they come. A proposed $18 \%$ cut to the Department of Energy's Office of Science 2011 budget would require a cut of $30 \%$ over the remaining seven months of the fiscal year. At the Thomas Jefferson facility, that would mean the suspension of the accelerator upgrade, McKeown says, and lay-offs for 300 of the roughly 800 staff members working on the site.

Astronomer Scott Tremaine of the Institute for Advanced Study in Princeton, New Jersey - who advised on the National Academy of
Sciences' decadal survey of astronomy and astrophysics priorities in 2010 - says that the uncertainty highlights a major problem of the US system. Budgets are set year-to-year - or, at the moment, fortnight-to-fortnight through congressional negotiations, so longterm, international collaborations are difficult to plan, and assumptions about future budgets are liable to be wrong. For example, the decadal survey worked with figures from NASA projecting a flat budget over the coming decade, and with figures from the National Science Foundation that assumed a doubling of funds relative to a 2007 baseline. Now, says Tremaine, "that is looking unrealistic".

Additional reporting by Meredith Wadman.

\title{
Risky energy research faces uncertain future
}

\section{ARPA-E's aggressive approach to managing research wins support - but perhaps not federal dollars.}

\section{BY JEFF TOLLEFSON}

$\mathrm{W}$ hen the US energy department's new agency for high-risk, highimpact energy research announced a competition for carbon-capture technologies in December 2009, David Sholl decided to take the plunge. Sholl and his colleagues at the Georgia Institute of Technology in Atlanta had an idea for membranes that make use of a new class of porous crystalline compound to filter carbon dioxide from power-plant exhaust. A month later they had submitted a proposal to the agency, called ARPA-E (Advanced Research
Projects Agency-Energy), and in April 2010 they won a US\$1-million, two-year award.

The first money arrived in July, and two weeks later, Sholl says, his team got a lesson in ARPA-E's hands-on style. "They started calling and saying, 'What have you got done?'” Sholl says. "I'm used to the money-over-the-fence approach with science funding, but this is a much more collaborative sort of relationship." A year into the first round of projects funded by ARPA-E, scientists, businesses and venture capitalists say that the model is already creating a powerful ecosystem that cultivates entrepreneurial science. At least six ARPA-E projects, targeting technologies from solar power to wind energy and batteries, have already gone on to earn additional backing from venture capitalists, and President Barack Obama's administration is eager to scale up the programme. But budget cutting in Congress could stifle the agency before it has a chance to prove itself.

ARPA-E, which received its first funding in 2009, was modelled on the Defense Advanced Research Projects Agency (DARPA), famous for its development of the Internet. Like DARPA, ARPA-E seeks to identify gamechanging ideas that are too radical for agencies such as the National Science Foundation. Its research managers then actively cultivate each project, unlike the hands-off approach taken by basic-research agencies.

The approach leaves little room for serendipity, but Sholl says that it is an effective way to keep research moving and focused on a specific, commercially relevant goal. "One of the huge advantages of the ARPA-E programme is that there is a well-defined industrial target," he says. "ARPA-E is kind of god's gift to venture capital," agrees Matthew Nordan, vice-president of the venture-capital firm Venrock in Cambridge, Massachusetts. "It

\section{ENERGV INVESTMENT | ARPA-E has rolled out grants for more than 100 projects in the past year and a half, ranging from electrofuels (transportation fuels produced from carbon dioxide) to energy-storage technologies for the grid.}

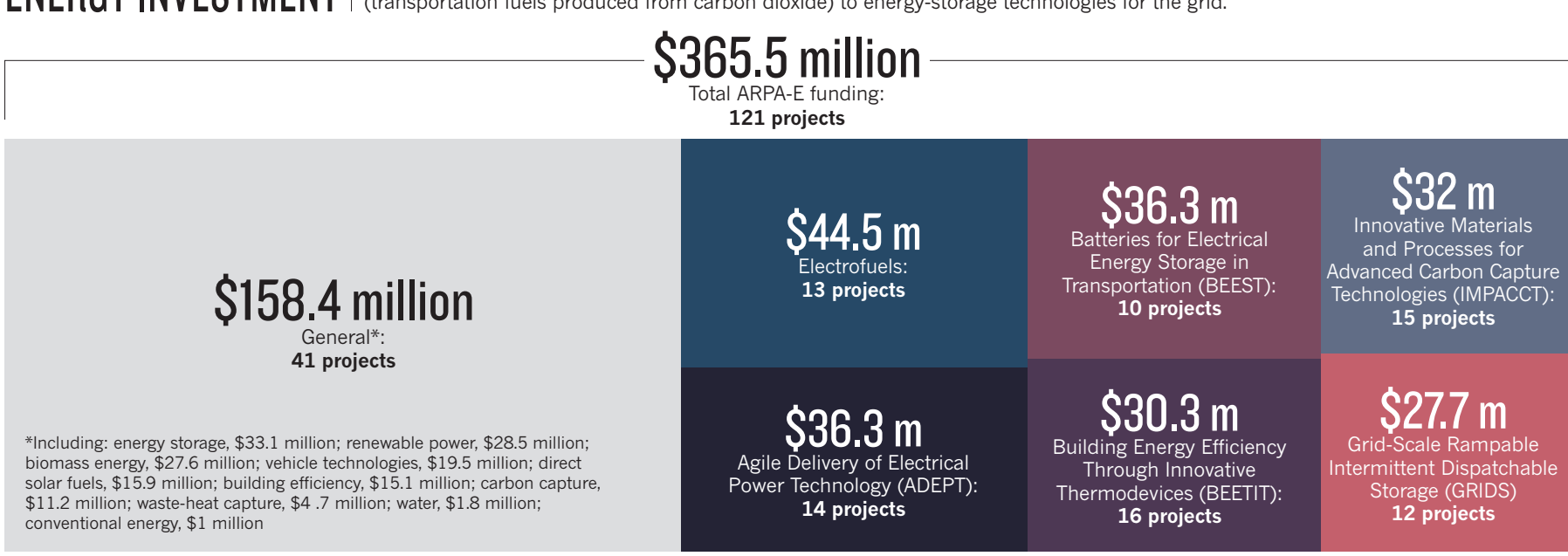


- provides an independent yardstick as to whether something is interesting enough and whether it meets its yard posts."

At ARPA-E's second annual Energy Innovation Summit in Washington DC last week, the mood was upbeat and the speeches were inspirational, underscoring science's role in keeping the United States competitive in the global race for clean energy. But the fiscal backdrop is ominous. In Congress, Democrats and Republicans remain at loggerheads over federal spending, having temporarily averted a government shutdown last week when the House of Representatives passed a resolution that funds the government until 18 March (see page 144). Although the White House proposed a budget of $\$ 300$ million for ARPA-E in the current fiscal year, the continuing resolution contains just $\$ 50$ million for the agency, enough to launch at most one new research programme.

To date, the agency has committed $\$ 365.5$ million to 121 projects in various fields (see 'Energy investment'). But all of that money came from the original \$400-million appropriation in the economic stimulus package enacted in April 2009. Depending on how much more money comes through this year, the agency is already considering several new programmes in areas such as solar photovoltaics, the conversion of natural gas into liquid fuels, and energy technologies that reduce the consumption of water, rareearth metals and other crucial materials. For fiscal year 2012, the administration has requested $\$ 550$ million, which should allow further expansion.

ARPA-E director Arun Majumdar says that the agency is ready to move ahead once Congress resolves its funding for this year and next. But he received mixed messages from two Republican senators who attended the conference, Lisa Murkowski of Alaska and Lamar Alexander of Tennessee. Both lawmakers, while offering their support for ARPA-E, warned that Congress is in full budget-cutting mode.

The agency will soon begin making difficult choices about its first round of projects. Each project has measurable milestones, and Majumdar says that the agency will put each one on green, yellow and red alerts depending on how much progress it has made. Project managers will continue to work with the scientists to help them meet their targets, but yellow and red signal trouble if researchers don't start to make progress.

"We will help you as much as we can, but if it doesn't work, it doesn't work," Majum- $\rightarrow$ NATURE.COM

For more on clean energy see:

go.nature.com/ebumpw dar says. "Taxpayer money should not be given to things we know are not going to work." -

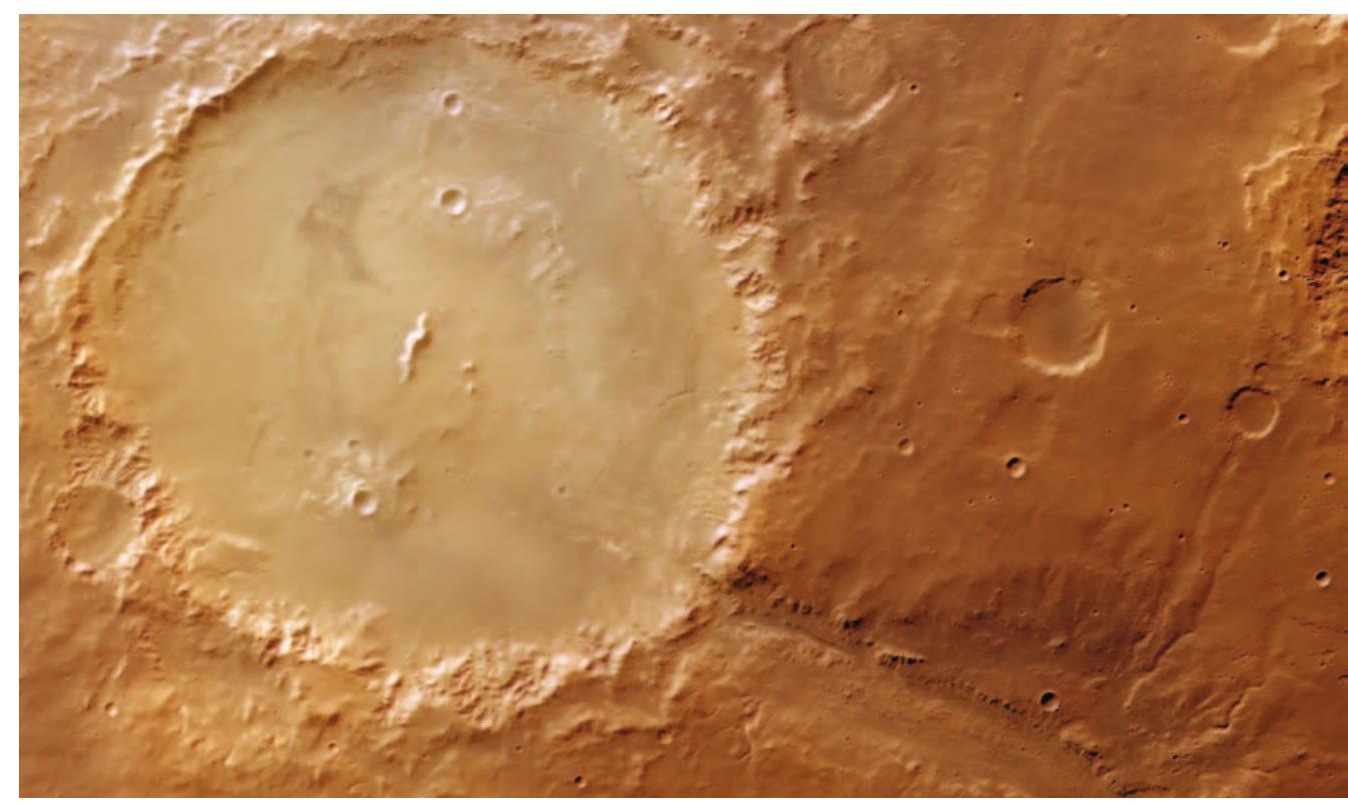

Mars's 150-kilometre Holden Crater, which shows signs of a watery past, could be perfect for rock hunting.

PLANETARY SCIENCE

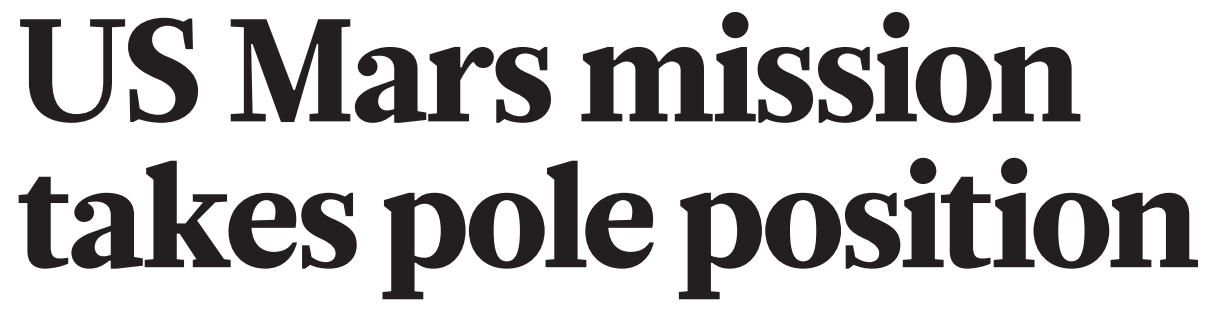

Sample-return trip to go ahead, but only if costs can be cut.

\section{BY ADAM MANN}

A showdown over the course of Solar System exploration has ended with a qualified victory for Mars. NASA's planetary-science decadal survey, which sets mission priorities for 2013-22, firmly favours a mission to Mars over a rival one to Jupiter's icy moon Europa (see Nature 466, 168-169; 2010). But the decision marks the beginning of a much bigger battle: to secure the budget to lift the multibillion-dollar project off the survey's pages and into the heavens.

The decadal-survey committee's recommendations, released on 7 March at the Lunar and Planetary Science Conference in Houston, Texas, relied partly on President Barack Obama's 2011 budget request, which projected that NASA's annual planetary-science funding would grow from its current allocation of $\$ 1.36$ billion to more than $\$ 1.6$ billion by 2015 . But Obama's 2012 budget foresees that funding dropping to $\$ 1.2$ billion in 2016. On 3 March, planetary-sciences division director James Green told the NASA Advisory Council's science committee that this would create indefinite delays for both the Mars and Europa missions.

"This creates a big gap between what the decadal survey is planning on and what is available," agrees Fran Bagenal, a planetary scientist at the University of Colorado, Boulder, and former chairwoman of an external NASA planetary-science advisory committee, who was not involved in creating the report.

The details of the recommendation reflect the committee's attempts to navigate different budget scenarios and maintain a robust $c$ research agenda under cash-strapped conditions. "In prioritizing missions, the most important criterion was maximizing science bang per buck," says Steve Squyres, an astronomer at Cornell University in Ithaca, New York, and chairman of the decadal survey.

The top-ranked flagship mission, the Mars Astrobiology Explorer-Cacher (MAX-C), would use a rover to conduct in situ astrobiological experiments, and to collect and store samples for return to Earth. This mission would also deliver the ExoMars rover for the European Space Agency (ESA). "We are at the point in Solar System exploration where what we want to do is beyond the budget of a single nation," says Wendy Calvin, a geologist at the University of Nevada, Reno, and vice-chair of the decadal survey's Mars panel.

To allow room in the budget for other priorities, the report recommends that the mission should not fly in the next decade 